\title{
Digital TV Accessibility - analogue switch off in Europe and Africa
}

\author{
Takebumi ITAGAKI ${ }^{1}$, Thomas OWENS ${ }^{1}$, Pilar ORERO ${ }^{2}$ \\ ${ }^{1}$ Department of Electronic and Computer Engineering, College of Engineering, Design and \\ Physical Sciences, Brunel University London, Uxbridge UB8 3PH, United Kingdom \\ Tel: +44 1895 266749, Fax: +44 1895 269782, \\ Email:Takebumi.Itagaki@brunel.ac.uk,Thomas.Owens@brunel.ac.uk \\ ${ }^{2}$ Faculty of Translation, Universitat Autònoma de Barcelona, Campus UAB, \\ 08193 Bellaterra-Barcelona, Spain \\ Tel: +34 226751 958, Email: pilar.orero@uab.cat
}

\begin{abstract}
June 2015 was the deadline for the switchover from analogue to Digital Terrestrial Television (DTV) in Europe, Africa, the Middle East and Central Asia. The DTV4ALL Project was a project funded by the European Commission under the CIP ICT Policy Support Programme to facilitate the provision of access services on digital television across the European Union; The call for proposals under which the project was funded was issued in response to the switch-off of analogue terrestrial television service in Europe being set to begin in 2012. The motivation for the call was to ensure the switchover would take place in such a way as to be favourable to the provision of access services. This paper summarises the main lessons learned from the DTV4ALL Project in terms of the provision of access services on DTV and highlights their possible application in Africa for the purposes of fostering e-inclusion and e-accessibility through digital TV.
\end{abstract}

Keywords: ICT for e-inclusion and e-accessibility, Content Technologies: Language, Learning

\section{Introduction}

The deadline that applied in Europe for the switchover from analogue to Digital Terrestrial Television (DTT) was 00:01 UTC on 17 June 2015 and was intended to herald the development of 'all-digital' terrestrial broadcast services for sound and television in all of the 119 countries belonging to ITU Region-1 (Europe, Africa, the Middle East and Central Asia) [1]. However, in an African context while East African countries switched off their analogue terrestrial TV services ahead of the deadline [2] other African countries were not ready to meet the deadline. For example, South Africa has delayed their analogue switchoff [3].

DTV4ALL was a project funded by the European Commission, under the CIP ICT Policy Support Programme to facilitate the provision of access services on digital television across the European Union [4,5], it started July 2008 and ended March 2011. The ICT Policy Support Programme (PSP) aimed at stimulating innovation and competitiveness through the wider uptake and best use of ICT by citizens, governments and businesses. Hence, the DTV4ALL project was totally different from a traditional Research Technology Development (RTD) project. Its focus was on the use of technologies developed in RTD projects in real contexts. In DTV4ALL digital TV technologies partly developed in FP4 to FP6 RTD projects were deployed in the public domain in terms of public terrestrial 
broadcasting. Specifically these technologies were used to demonstrate that the switchover to DTV offered the capability to widen service accessibility, by exploiting the increased broadcast capacity and service sophistication enabled by the switchover, through the provision of enhanced subtitling for the hard of hearing or deaf and audio description services for the partially sighted or blind.

The EU deadline for the analogue switch off was originally planned for the end of 2012 and represented both a challenge as well as an opportunity for access services. It represented a challenge for two very different reasons. Firstly, many people who had no problems accessing analogue television services could experience some difficulty in accessing digital television services. Secondly the analogue switch-off was expected to result in widespread improvements to the quality of existing digital television programmes, collectively known as $2^{\text {nd }}$ generation digital television, which threatened the provision of access services. In particular, while the increased amount of information that can be broadcast by a digital terrestrial television transmitter compared with an analogue transmitter makes the transmission of high definition television (HDTV) possible, the increase in broadcast capacity is not so great that the demand for HDTV that does not pose a potential threat to that part of the capacity set aside for provision of access services. So existing access services had to be defended and while additional access services could be offered it was essential to make a very strong case for such services if there was to be any realistic chance of their being provided. .

People who are hard of hearing or deaf need subtitles or deaf signing to be provided with television programmes if they are to fully appreciate its dialogue. People who are partially sighted or blind need audio description provided with a television programme if they are to fully appreciate the context of what they hear. Such services enable their users to access the storyline of a television programme so are known as access services. In current digital TV standards, there are several standards for conveying subtitles. In theory, the MPEG 2 format can convey not only 5.1 channel stereo, mp3 (MPEG 1 Audio layer 3) can carry up to 48 separate audio channels. So, one audio channel could be devoted to audio description for the partially sighted or blind, another for clean audio (dialogue only without background sound) for the hearing impaired, and another in a different language etc., as long as the radio frequency bandwidth is available. Therefore, all the standards need to deliver digital TV services are available. However, their integration is another matter.

When these services are introduced, careful planning and comprehensive deployment strategies are essential as a large part of the target audience must have an appropriate receiver and the broadcaster must follow the guidelines for the content production and transmission. In the case of a private broadcaster, such as a subscription TV provider, it is very easy to control the whole service delivery chain and part of the subscription costs covers the receiver. On the other hand, a public broadcaster may not be able to control all of its delivery chain, especially the end user terminal development and production, thus deployment planning based on deployment strategies developed by a national regulatory body is a must.

The opportunities to improve access to digital television for those with physical, mental or age-related impairments that arise due from analogue switch-off take two forms, opportunities to extend the provision of existing mature access services to countries that do not currently provide them, and opportunities to provide new kinds of access services known as emerging access services. The most valuable contribution DTV4ALL could make 
was to identify the enablers that would allow a core set of access services to be offered in all EU member countries in the near future. The objectives of DTV4ALL project were;

1. Offer and evaluate mature subtitling, audio description, audio subtitling and signing services in a minimum of four territories within the European Union for at least 12 months.

2. Identify improvements to existing access services offered in some European countries and ways of addressing the key technical, organisational and legal obstacles to the sustainable take-up of these services throughout Europe in the timeframe 2008-2010.

3. Identify and prioritise key emerging access services, and the devices and platforms needed to support them for the period 2010-2012 in terms of technological feasibility, perceived value to their intended users and business model viability.

4. Make recommendations regarding mature and emerging access services to bodies representing stakeholders in the access service value chain on the basis of which these bodies can take appropriate action in relevant standardisation bodies.

\section{Lessons Learned from the DTV4ALL Project}

\subsection{Current Situation in EU member countries}

In Europe most of the plans for the deployment of accessible Digital Terrestrial Television transmitters were complete. On the transmission side:

- The Digital Video Broadcasting (DVB) standard is in use

$\rightarrow$ DVB subtitles can be sent

- The MPEG-2 audio/video standard is in use (with some use of the MPEG-4 video standard)

$\rightarrow$ Audio (sound only) access services can be sent on a dedicated audio channel (e.g. Audio Description (AD), clear audio, etc.)

$\rightarrow$ An extra video stream (e.g. of a signer) could be sent in the private section of an MPEG-2 Transport Stream, or a secondary Transport Stream on another channel could be superimposed over the main content, for this, a secondary tuner and dedicated functionality in the receiver middleware might be required.

The necessary standards for delivery of mature access services on DTV are available or being implemented. However, it seems that operational issues, such as the provision of guidelines on receiver middleware functionality, may have to be clarified in some countries.

As long as enough radio frequency resource (spectrum/capacity) is available the access services mentioned above could be transmitted for "user mix" reception, i.e. the user can select to use or not use the services. However, at the receiver end:

- UK and NORDIG member countries have middleware implementation guidelines and receiver compliance validation systems, e.g., Digital Television Group's (DTG) "Digital Zoo" in the UK.

- Most of the other EU member countries do not have middleware implementation guidelines: 
$\rightarrow$ Receivers in these countries may not be able to present unanticipated access service content within a DVB transport stream and/or encapsulated within MPEG-2 streams.

$\rightarrow$ Access service content may confuse the receiver resulting in a complete loss of service, undesired presentation of the service to the user and/or an incorrect presentation of the service to the user, as reported in DTV4ALL pilot test results gathered by RBB (Berlin, Germany).

$\rightarrow$ The Commission needs to address the policy actions that need to be taken to remedy the above situation.

Some EU member countries, in particular Germany, have decided to take another approach to future TV, Hybrid TV (HbbTV) with a broadband Internet connection. In these cases, no further developments are to be expected on existing broadcasting services. This is not an option for many EU member countries, because of a lack of affordable broadband Internet services to the home.

\subsection{Developments}

There were several EU directives on switchover, including one for "Digital Terrestrial TV Switch on by 2012". However, the DTV4ALL project has identified that a pan-European approach may not be always suitable because the flow of regulatory planning and of funding for public broadcasting is at the national level.

Technically, each EU member country controls its own regulatory environment for terrestrial broadcasting. This state of affairs is reflected in the International Telecommunication Union (ITU) through one member one vote for each nation state. The ITU allocates Radio Frequency Spectrum and other related resources at a global level. The manufacturers and broadcasters can be represented through a member country. The European Broadcasting Union (EBU) could co-ordinate an action among the EBU member countries, but such an action has to be initiated from the bottom up by member countries.

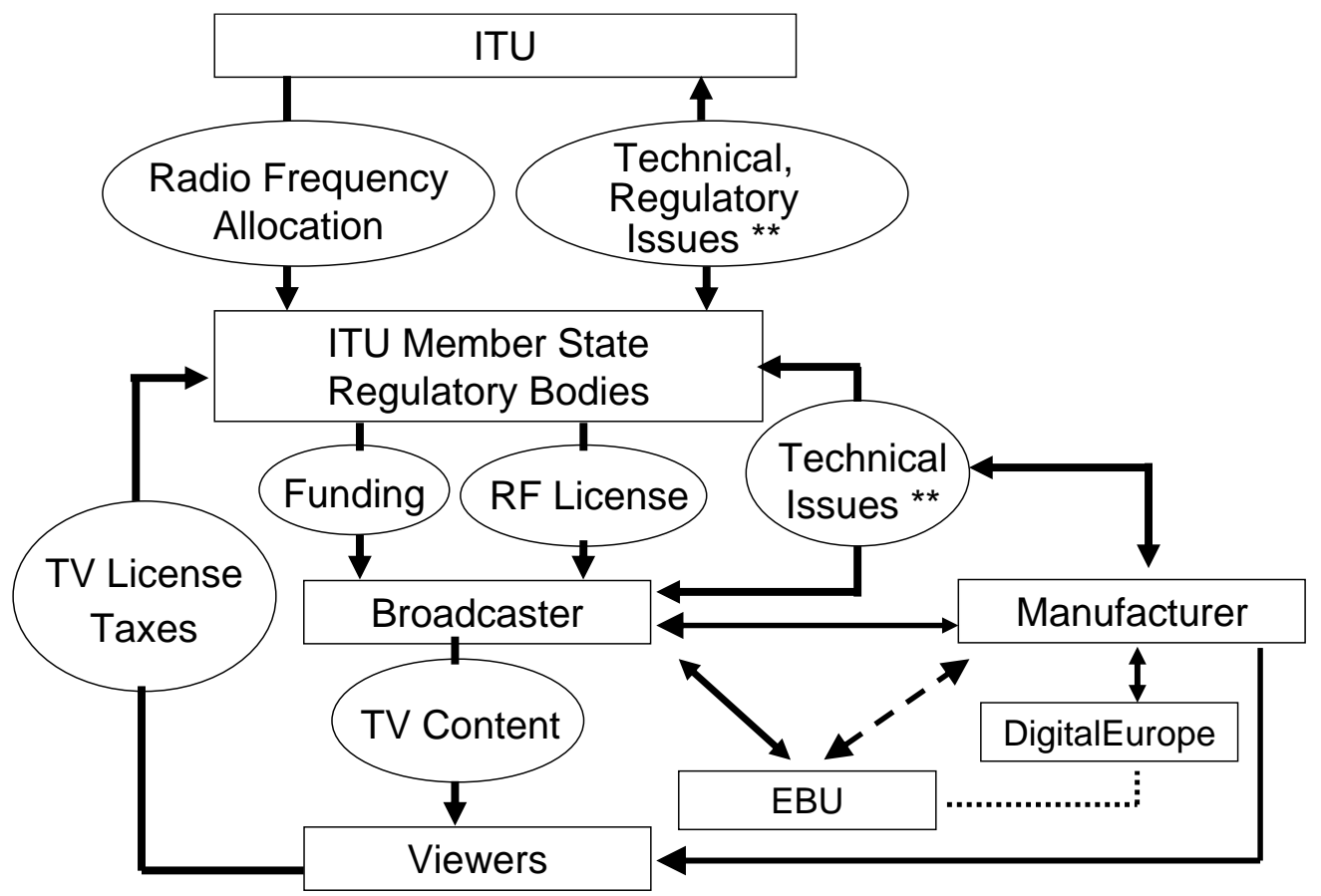

Figure 1: Flow of regulatory control and of funding in terrestrial public broadcasting 
The DTV4ALL project identified that for the roll out of access services for terrestrial television to be accelerated it is necessary to acknowledge that:

- The remit of Europe's national broadcast regulatory bodies requires:

- A country by country approach

- Coordination of the national regulatory bodies through EU

- A pan-European technical solution for the delivery of access services by terrestrial broadcast may not be needed as existing standards could be used with minor changes to receiver middleware. As a result, some manufacturers choose to use a pan-European platform for their high-end integrated Digital TV with some minor modification on their middleware to reflect local differences.

\subsection{European Solutions}

The philosophy of approach that emerged from the work of the DTV4ALL project, underpinning its advice to the European Commission (EC) in its role as a policy support project, was that there is a need for the EC to make clear that if member states do not provide unequivocal evidence that substantial progress is being made on the roll out of access services for digital terrestrial television then by a certain date then national legislation will have to be introduced to ensure that such access services are provided.

Currently, any legislation requiring the provision of access services for digital television would have to be introduced at the national and not the European level for reasons that include:

- The speed of terrestrial digital TV deployment is different from country to country.

- At the national level local conditions such as the availability of spectrum and of high speed broadband connections can be fully and efficiently taken into account.

- Only member countries' national regulatory bodies have the power of licensing and funding as the ITU allocates frequency resource to each member country without EC involvement.

- There are no EU-wide regulatory bodies that oversee broadcasting policy. Hence, the EC may wish to consider establishing a regulatory body for terrestrial broadcasting similar to the one that oversees telecoms policy. i.e., the Body of European Regulators for Electronic Communications (BEREC).

National legislation has already had a significant positive impact on the provision of access services in, for example, United Kingdom, Demark and Spain. It is worth noting that these countries have a long-term road map for analogue to digital TV switchover that includes a technical forum for middleware/equipment and a user forum under the control of the regulatory bodies.

On $29^{\text {th }}$ November 2007 the European Parliament issued the 'Audiovisual Media Services Without Frontiers' Directive, which gives rights to better access to audiovisual media, including television programmes, to hearing or visually impaired citizens. The directive identified the need for converged regulation in an environment where increasingly audiovisual media is delivered over converged networks. Article 7: Accessibility for people with disabilities states that [8]: 
"Member States shall encourage media service providers under their jurisdiction to ensure that their services are gradually made accessible to people with a visual or hearing disability."

"Sight- and hearing-impaired persons as well as elderly people shall participate in the social and cultural life of the European Union. Therefore, they shall have access to audiovisual media services. Governments must encourage media companies under their jurisdiction to do this, e.g. by sign language, subtitling, audiodescription or easily understandable menu navigation."

EU member states were given 24 months to move these provisions into national law so they should have applied by 2009.

As the United Nations convention on the rights of persons with disabilities [9] came into force in 2008 such action is now essential so that all EU member states are compliant with this convention. The work of the DTV4ALL Project became a part of a "Focus Group on Audiovisual Media Accessibility" of the International Telecommunication Union (ITU) [10]. The Focus Group was concluded in October 2013, but work audiovisual media accessibility in the ITU continues.

In addition to their widely familiar use as aids for people with sight or hearing impairments, access services are used in Europe to promote the social inclusion of immigrant and national minority groups. For example, alternative audio channels are provided in Catalonia (Spain) and Finland which give the dialogue of popular television programmes in the languages of significant immigrant groups so that they can more readily access the content of the programmes and thus become more aware of the cultural and social issues, and the values of the society around them. The technology required to provide such services is the same as that used to provide an alternative audio channel delivering audio description to blind users. Other access services also promote the social integration of minority groups. For example, having available subtitles in your native language accompanying audio visual material in a language that is foreign to you can greatly assist in your learning of the foreign language.

\subsection{A step forward in Europe}

The UN Convention on the Rights of Persons with Disabilities contains accessibility obligations. It requires that its parties, like the EU and its Member States, take the necessary measures, including legislation to ensure accessibility. Without EU action, each EU country will continue to develop different laws as they implement their obligations, increasingly fragmenting the EU market. Media accessibility has been identified as a critical issue in Europe. The new European Accessibility Act [11] shows the European Commission pledge to set common accessibility requirements at an EU level for certain key products and services that will help people with disabilities participate fully in society. The EC following the success of DTV4ALL has continued funding projects related to media accessibility and the new EU broadcast and broadband standard HbbTV.

HbbTV (Hybrid Broadcast Broadband TV) [12] is an open, standard specification for Connected TV, supported by a group of stakeholders and published by the ETSI (European Telecommunications Standards Institute). HbbTV allows both broadcasters and TV-set manufacturers to exploit multimedia content via Internet. For this reason, HbbTV is a valid specification for horizontal markets, such as digital terrestrial television and free-to-air satellite broadcasting. 
This article has been accepted for publication in a future issue of this conference proceedings, but has not been fully edited. Content may change prior to final publication. Citation information: DOI10.1109/ISTAFRICA.2016.7530658, 2016 IST-Africa Week Conference

HBB4ALL [13] (Hybrid Broadcast Broadband For All) is a European project co-funded by the European Commission inside the Competitiveness and Innovation Framework Programme (CIP). The HBB4ALL project typology, as its predecessor DTV4ALL, is "pilot", since it takes advantage of new but already validated technologies (HbbTV in this case) to deploy near-market services in real exploitation conditions. Moreover, HBB4ALL aims at optimising services while providing a fully satisfying user experience.

The presence in the HBB4ALL consortium of relevant European broadcasters established across Europe ensures a potential audience of millions of citizens at the pilot sites. This fact will allow checking the HbbTV-based access services in large-scale conditions. Europe as a testbed is quite interesting since all translation traditions coexist: dubbing, subtitling and voice-over. These have direct implications on how to deploy access services, since for example audio description is created differently for a dubbed movie, a subtitled movie, and a movie with voice-over. More interestingly Europe offers also a rich background of languages, with large and small user communities, under different conditions: monolingual, bilingual and multilingual societies. Testing under these conditions makes the findings of both DTV4ALL and HBB4ALL valid many countries outside Europe.

HBB4ALL consists of four different but inter-related pilots:

- Pilot A. Multi-platform subtitle services

- Pilot B. Alternative audio production and distribution

- Pilot C. Automatic user interface adaptation and accessible Connected TV applications

- Pilot D. Sign language interpretation

The planning of these pilots consists of the same four phases, the of core which is the "operational phase", starting in summer 2015 and running at the time of writing this article.

\section{Application of the lessons of DTV4ALL to African contexts}

The ITU set $17^{\text {th }}$ June 2015 as the deadline for the switchover from analogue to Digital Terrestrial Television in Europe, Africa, the Middle East and Central Asia. As ITU member nations, the African counties ought to observe the deadline. Furthermore, the African counties are the members of the United Nations (UN) so the UN convention on the rights of persons with disabilities applies and African governments have to establish and enforce appropriate regulatory requirements on accessibility to be compliant with the convention. This applies to Digital TV as well as essential services.

African nations have deployed digital terrestrial TV with and without accessibility elements. Some African nations are going to deploy DTV access services in near future. From the European experience, it is relatively difficult to retro-fit additional DTV services once an initial DTV deployment is completed. The most difficult obstacle is the spectrum availability in a multiplexed transmission. Once the specification is fixed, it is very difficult to change. This would apply to the countries that adopted the DVB-T and DVB-T2 broadcast standards. In the case of a country that adopted ISDB-T, e.g. Botswana, as the spectrum control within a transmission channel is the responsibility of the TV station that was allocated the transmission channel it is easier to introduce new services, however, there may still be some problems in doing so related to the player software on receivers.

For effective implementation of access services, it is essential to have a 'national' forum like DTG in the UK or NORDIG in the Scandinavian countries, which brings 
together representatives of the public broadcasters, users, equipment/STB manufacturers and the regulatory bodies. Also, it is necessary to develop content creators including of subtitles, clear audio services, audio description and signing services, etc. For some major languages, there are several speech-to-subtitle generation software tools available in the commercial market. However, other services are rather labour intensive to provide. To exploit existing standards for other purposes, such as providing multi-lingual TV programmes etc. the above mentioned forum would be needed as broadcasters and the receiver manufacturers must agree on a protocol for the end-to-end delivery of the service.

\section{Concluding remarks}

There may not be a significant difference in a business model for a public owned Digital Terrestrial TV broadcaster in Europe and one in Africa, thus the lessons learnt from the European situations can be applied to Africa. If a Digital Terrestrial TV deployment in Africa has been done with DVB-T/-T2 or ISDB-T without access service provisions, there needs to be a retrofitting of the services in light of the UN convention on the rights of persons with disabilities. Depending on the technical provisions implemented, some access services could be retrofitted, but with costly consequences: changes in receivers and their remote control etc. If a DTT deployment has not been done some time will be available to revise the deployment planning for e-accessibility and e-inclusion. Also content exchange between DVB systems (DVB-T and DVB-T2) in most of the Africa, and the ISDB-T system in Botswana, could be possible, providing a set of guidelines for content creation is implemented to cover the technical/regulatory differences.

Brunel University London (UK) and its partners would be able to provide suggestions on the regulatory issues and technical provisions in English, whereas the Universitat Autònoma de Barcelona (Spain) and its partners would be able to provide suggestions on contents: subtitles, audio description and sign language provisions in English, Spanish, Catalan, French and Flemish.

\section{References}

[1] http://www.itu.int/net/pressoffice/press_releases/2015/25.aspx (08 Apr 16)

[2] http://www.africareview.com/News/East-Africa-gets-ready-for-2015-analogue-switch-offdeadline/-/979180/2571232/-/127rsko/-/index.html (08 Apr 16)

[3] http://www.digitaltveurope.net/334341/south-africa-delays-analogue-switch-off/ (08 Apr 16)

[4] http://www.psp-dtv4all.org/ (08 Apr 16)

[5] Itagaki, T., \& Owens, T. J. (2010). A medium to long term roadmap for access services on DTV. In P. Cunningham, \& M. Cunningham (Eds.), eChallenges e-2010 Conference Proceedings. Warsaw, Poland: IIMC International Information Management Corporation Ltd.

[6] http://cordis.europa.eu/project/rcn/191846_en.html (08 Apr 16)

[7] http://ec.europa.eu/information_society/activities/ict_psp/index_en.htm (08 Apr 16)

[8] http://ec.europa.eu/avpolicy/reg/tvwf/access/index_en.htm (08 Apr 16)

[9] http://www.un.org/disabilities/convention/conventionfull.shtml (08 Apr 16)

[10] http://www.itu.int/en/ITU-T/focusgroups/ava/Pages/default.aspx (08 Apr 16)

[11] http://ec.europa.eu/social/main.jsp?langId=en\&catId=89\&newsId=2400 (08 Apr 16) 
This article has been accepted for publication in a future issue of this conference proceedings, but has not been fully edited. Content may change prior to final publication. Citation information: DOI10.1109/ISTAFRICA.2016.7530658, 2016 IST-Africa Week Conference

[12] European Telecommunications Standards Institute (ETSI). TS 102796 "Hybrid Broadcast Broadband TV"

[13] http://www.hbb4all.eu/ (08 Apr 16) 